\title{
Cerebral Hemangioma
}

National Cancer Institute

\section{Source}

National Cancer Institute. Cerebral Hemangioma. NCI Thesaurus. Code C5433.

A hemangioma arising from the cerebral hemisphere. 